\title{
CHROMATOGRAPHIC STUDIES ON BIOACTIVE COMPOUNDS OF ETHANOLIC LEAF EXTRACT OF AERVA LANATA BY HIGH PERFORMANCE THIN LAYER CHROMATOGRAPHY TECHNIQUE
}

\author{
LUCIA SOUNDER ${ }^{1 *}$, VICTOR AROCKIA DOSS ${ }^{2}$ \\ ${ }^{1}$ Research and Development Centre, Bharathiar University, Coimbatore, ${ }^{2}$ Department of Biochemistry, PSG College of Arts and Science, \\ Coimbatore, Tamil Nadu, India. Email: sadam.success@gmail.com
}

Received: 16 December 2016, Revised and Accepted: 28 March 2017

\section{ABSTRACT}

Objective: This study was designed to determine the bioactive compounds such as alkaloids, glycosides, phenol, and tannins by high performance thin layer chromatography (HPTLC) which will help in crude drug identification and in the standardization of Aerva lanata in pharmacological industries.

Methods: HPTLC studies were conducted as Harborne described. The toluene-acetone-formic acid (4.5:4.5:1); ethyl acetate-ethanol-water (10:1.35:1); ethyl acetate-ethanol-water (8:2:1.2); toluene-ethyl acetate-formic acid-methanol (3:3:0.8:0.2) were employed as mobile phase for phenol, alkaloid, glycoside, and tannin profiles.

Result: The ethanolic extract of leaves of $A$. lanata illustrated the presence of 11 different types of phenol with 11 different Rf values with range 0.06 $0.95,10$ different types of alkaloid with 10 different Rf values from 0.02 to $0.92,12$ different types of glycoside with 12 different Rf values from 0.02 to $0.96,9$ different types of Tannin with 9 different Rf values from 0.07 to 0.93 .

Conclusion: This study supplements valuable information about known and unknown bioactive compounds with the bioactivity of $A$. lanata. Further, pharmacological studies on structure of the bioactive compounds can be formulated to treat diseases. Thus, the ethanolic extract of $A$. lanata plant can be utilized as a useful medicinal herb for alleviation of various illness and disorder.

Keywords: High performance thin layer chromatography, Alkaloids, Glycosides, Phenols, Tannins.

(C) 2017 The Authors. Published by Innovare Academic Sciences Pvt Ltd. This is an open access article under the CC BY license (http://creativecommons. org/licenses/by/4. 0/) DOI: http://dx.doi.org/10.22159/ajpcr.2017.v10i6.16658

\section{INTRODUCTION}

Herbal drugs have been in exercise in various parts of the world for centuries to treat a number of diseases. Today, the plant based medicines are being used worldwide as medications and suggest a broad spectrum of activity since ancient times. The drug efficiency depends on the several active principles and compounds present in it.

Like other plants, medicinal plants synthesize a vast range of organic compounds that are traditionally classified as primary and secondary metabolites. Primary metabolites are compounds that have essential roles associated with photosynthesis, respiration, growth, and development. These include phytosterols, acyl lipids, nucleotides, amino acids, and organic acids. Other phytochemicals, many of which accumulate in surprisingly high concentration in some species, are referred as secondary metabolites. It plays a key role in protecting plants from herbivorous and microbial infection, as attractants for pollinators and seed dispersing animals, as allelopathic agents, ultra violet (UV) protectants and signal molecules in the formation of nitrogen-fixing root nodules in legumes.

In recent years, the role of some secondary metabolites as protective dietary constituent has become an increasingly important area of human nutrition research. Medicinal plants antioxidant activity is mainly due to the presence of secondary metabolites. Based on their biosynthetic origins plant secondary metabolites can be divided into four major groups. Flavonoids, phenolics, terpenoids, and alkaloids are containing compounds.

The well-developed quality standards can be achieved only through systematic evaluation of the plant material using modern analytical techniques including thin layer chromatography (TLC) and high performance TLC (HPTLC). HPTLC is methods commonly applied for the identification, assay and the testing of purity, stability, dissolution, or content uniformity of raw materials (herbal and animal extracts, fermentation mixtures, drugs, and excipients) and formulated products [1]. To identify the bioactive compounds responsible for pharmacological activities, phytochemical studies have been conducted by several workers with the report of different kinds of bioactive compounds particularly saponins, steroids, terpenoids, etc. The main constraint in the use of traditional remedies is the lack of standardization of raw material, manufacturing process, and the final product. HPTLC is a valuable tool for identification because it can provide chromatographic fingerprints that can be visualized and stored as electronic images. However, to fulfill the lacuna, this study was intended to resolve the alkaloid, glycoside, tannin, and phenol profile present in the methanolic extract of leaves of Aerva lanata, which will be useful for the proper identification of commercial samples $[2,3]$

\section{METHODS}

A. lanata was collected from natural habitats, Coimbatore, Tamil Nadu, India. It was authenticated by (CPCSEA/No: 158/1999/CPCSEA). The fresh leaves were shade dried and ( $5 \mathrm{~g}$ ) of plant material was extracted with ethanol in Soxhlet apparatus for $3 \mathrm{hrs}$. Cooled, filtered the content and concentrated using vacuum flash evaporator. Dissolved the content with $1 \mathrm{ml}$ ethanol and centrifuged at $3000 \mathrm{rpm}$ for 5 minutes. This solution was used as test solution for HPTLC analysis.

\section{HPTLC analysis}

$2 \mu \mathrm{l}$ of test solution and $2 \mu \mathrm{l}$ of standard solution were loaded as $5 \mathrm{~mm}$ band length in the $3 \times 10$ Silica gel $60 \mathrm{~F}_{254}$ TLC plate using Hamilton syringe and CAMAG LINOMAT 5 instrument. The samples loaded plate was kept in TLC twin trough developing chamber (after saturated with solvent vapor) with respective mobile phase (phenols: toluene-acetoneformic acid at the ratio of 4.5:4.5:1; alkaloids: ethyl acetate-methanolwater at the ratio 10:1.35:1; glycoside: ethyl acetate-ethanol-water at 
the ratio 8:2:1.2; tannin: toluene-ethyl acetate-formic acid-methanol at the ratio $3: 3: 0.8: 0.2$ ) and the plate was developed up to $90 \mathrm{~mm}$. Linear ascending development was carried out in $20 \mathrm{~cm} \times 10 \mathrm{~cm}$ twin trough glass chamber saturated with the mobile phase and the chromatoplate development for two times with the same mobile phase to get food resolution of phytochemical contents. The developed plate was dried by hot air to evaporate solvents from the plate. The plate was kept in photo documentation chamber (CAMAG REPROSTAR 3) and captured the images at visible light, UV $254 \mathrm{~nm}$, and UV $366 \mathrm{~nm}$. The developed plate was sprayed with respective spray reagent (phenol: folin-Ciocalteu reagent, tannin: 5\% ferric chloride reagent, glycoside: LibermannBurchard reagent, alkaloid: dragendorff's reagent followed by $10 \%$ ethanolic sulfuric acid reagent) and dried at $100^{\circ} \mathrm{C}$ in a Hot air oven. The plate was photo-documented in visible light and UV $366 \mathrm{~nm}$ mode using photo documentation (CAMAG REPROSTAR 3) chamber. After derivatization, the plate was fixed in scanner stage (CAMAG TLC SCANNER 3) and scanning was done at UV $254 \mathrm{~nm}$. The peak table, peak display, and peak densitogram were noted. The software used was win CATS 1.3.4 version.

\section{RESULTS}

\section{HPTLC finger printing analysis of phenols}

HPTLC fingerprint analysis of ethanol extract of $A$. lanata illustrated the presence of 11 different types of phenol with 11 different $R f$ values with range 0.06-0.95 (Table 1). Ethanol extract of A. lanata is compared with standard quercetin along with peak densitogram (Figs. 1-3). Blue, Brown colored zone at visible mode was present in the track, it was observed from the chromatogram after derivatization, which confirmed the presence of phenol/phenol carboxylic acid in the given standard and may be in the sample.

\section{HPTLC finger printing analysis of alkaloid}

HPTLC fingerprint analysis of ethanol extract of $A$. lanata illustrated the presence of 10 different types of alkaloid with 10 different Rf values from 0.02 to 0.92 (Table 2). Ethanol extract of A. lanata is compared
Table 1: Phenolic profile of the ethanolic extract of the leaf of A. lanata

\begin{tabular}{llllll}
\hline Track & Peak & Rf & Height & Area & $\begin{array}{l}\text { Assigned } \\
\text { substance }\end{array}$ \\
\hline Sample A & 1 & 0.06 & 38.7 & 766.7 & Unknown \\
Sample A & 2 & 0.15 & 15.5 & 600.4 & Unknown \\
Sample A & 3 & 0.22 & 54.8 & 1195.8 & Unknown \\
Sample A & 4 & 0.32 & 10.9 & 293.9 & Unknown \\
Sample A & 5 & 0.43 & 35 & 905.9 & Unknown \\
Sample A & 6 & 0.59 & 10.8 & 222.2 & Unknown \\
Sample A & 7 & 0.66 & 37.8 & 868.1 & Unknown \\
Sample A & 8 & 0.75 & 385.8 & 18826.5 & Phenolic 1 \\
Sample A & 9 & 0.81 & 276 & 12465.9 & Unknown \\
Sample A & 10 & 0.88 & 196 & 8805 & Unknown \\
Sample A & 11 & 0.95 & 242.5 & 10706.6 & Unknown \\
STD & 1 & 0.77 & 280.1 & 7949.1 & Quercetin \\
\hline
\end{tabular}

A. lanata: Aerva lanata

Table 2: Alkaloid profile of the ethanolic extract of the leaf of A. Ianata

\begin{tabular}{llllll}
\hline Track & Peak & Rf & Height & Area & $\begin{array}{l}\text { Assigned } \\
\text { substance }\end{array}$ \\
\hline Sample A & 1 & 0.02 & 132.1 & 2940.3 & Unknown \\
Sample A & 2 & 0.11 & 13.8 & 521.8 & Unknown \\
Sample A & 3 & 0.30 & 114.9 & 4493.6 & Unknown \\
Sample A & 4 & 0.34 & 154.1 & 8741.1 & Unknown \\
Sample A & 5 & 0.44 & 50.3 & 2189.7 & Unknown \\
Sample A & 6 & 0.57 & 336.2 & 16341.5 & Alkaloid 1 \\
Sample A & 7 & 0.66 & 121.8 & 3936.6 & Unknown \\
Sample A & 8 & 0.75 & 287.9 & 18920.0 & Unknown \\
Sample A & 9 & 0.89 & 599.1 & 38489.9 & Unknown \\
Sample A & 10 & 0.92 & 526.2 & 19452.9 & Alkaloid 2 \\
STD & 1 & 0.46 & 616.2 & 19452.9 & Colchicine \\
\hline A.lanata:Aerine
\end{tabular}

A. lanata: Aerva lanata

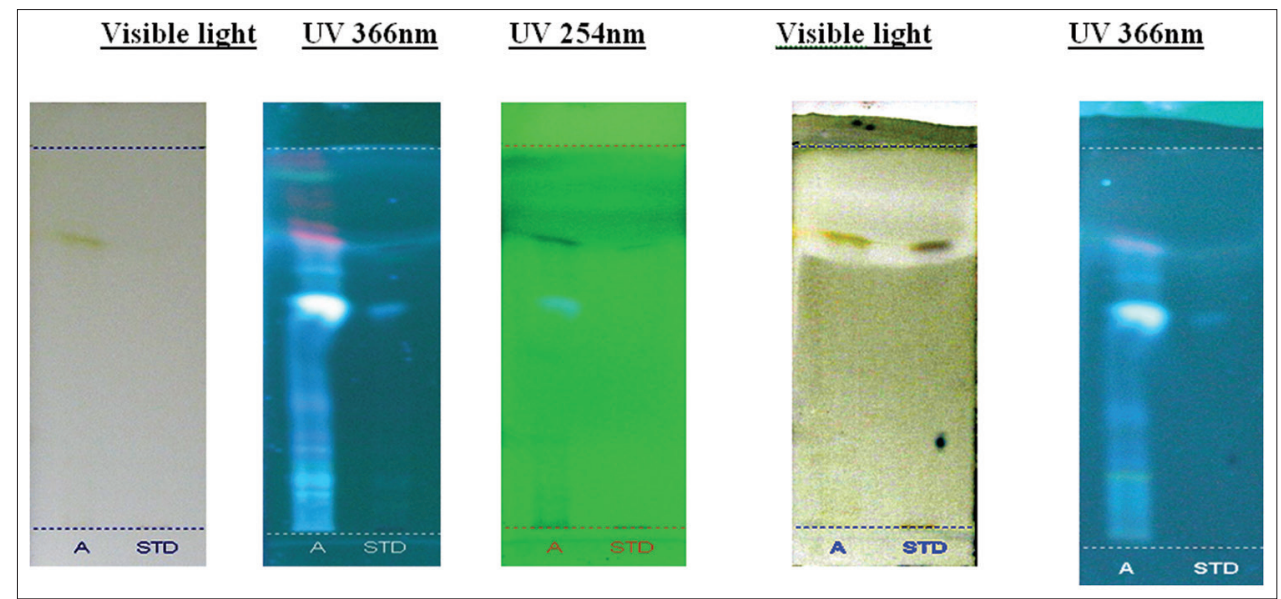

Fig. 1: High performance thin layer chromatography profile of the ethanolic extract of Aerva lanata and phenolic standard (quercetin)

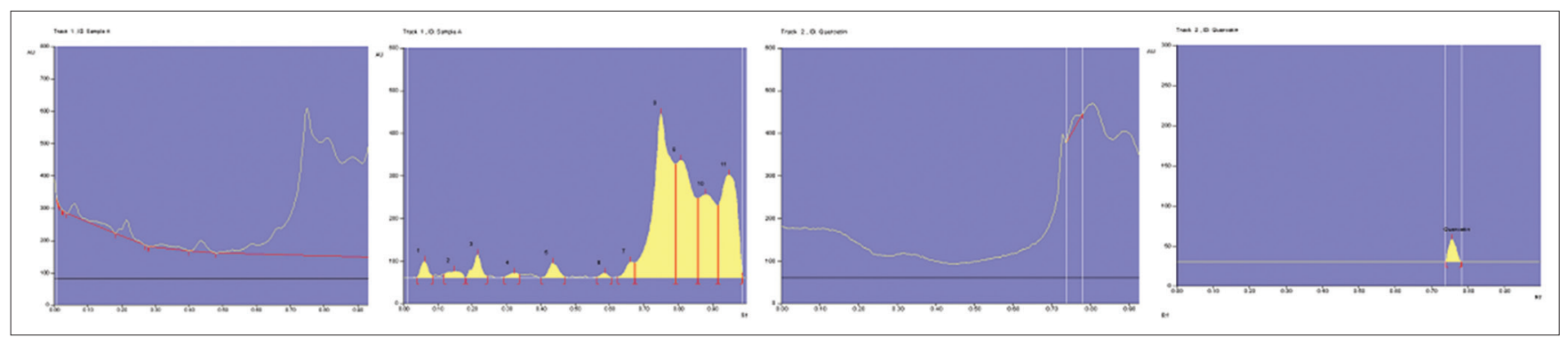

Fig. 2: High performance thin layer chromatography phenolic chromatogram of Aerva lanata leaf and phenolic standard (quercetin) - baseline display and peak densitogram display (scanned at $254 \mathrm{~nm}$ ) 
with Standard Colchicine along with peak densitogram (Figs. 4-6). Yellow, Brownish yellow colored zone at visible light mode were present in the tracks, it was observed from the chromatogram after derivatization, which confirmed the presence of alkaloid in the given standard and may be in the sample.

HPTLC fingerprint analysis of ethanol extract of $A$. lanata illustrated the presence of 12 different types of glycoside with 12 different Rf values from 0.02 to 0.96 (Table 3). Ethanol extract of A. lanata is compared with standard Swertiamarin along with peak densitogram (Figs. 7-9). Green colored fluorescent zone at UV $366 \mathrm{~nm}$ mode was present in the tracks, it was observed from the chromatogram after derivatization,

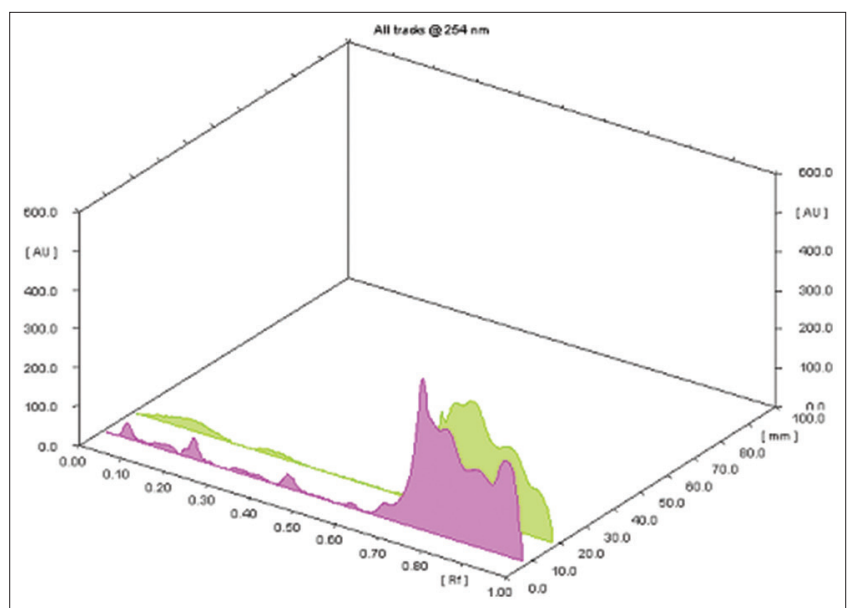

Fig. 3: 3D display of high performance thin layer chromatography phenolic chromatogram of Aerva lanata which confirmed the presence of glycoside in the given standard and may be in the sample.

\section{HPTLC finger printing analysis of tannin}

HPTLC fingerprint analysis of ethanol extract of $A$. lanata illustrated the presence of 9 different types of Tannin with 9 different $\mathrm{Rf}$ values from 0.07 to 0.93 (Table 4). Ethanol extract of A. lanata is compared with standard gallic acid along with peak densitogram (Figs. 10-12). Green, brownish green and yellowish green colored zone at visible light mode were present in the tracks, it was observed from the chromatogram after derivatization, which confirmed the presence of tannin in the given standard and may be in the sample.

Table 3: Glycoside profile of the ethanolic extract of the leaf of A. lanata

\begin{tabular}{llllll}
\hline Track & Peak & Rf & Height & Area & $\begin{array}{l}\text { Assigned } \\
\text { substance }\end{array}$ \\
\hline Sample A & 1 & 0.02 & 190.4 & 2503.0 & Unknown \\
Sample A & 2 & 0.06 & 10.5 & 113.2 & Unknown \\
Sample A & 3 & 0.10 & 13.0 & 184.6 & Unknown \\
Sample A & 4 & 0.16 & 13.1 & 171.2 & Unknown \\
Sample A & 5 & 0.20 & 15.7 & 264.6 & Unknown \\
Sample A & 6 & 0.37 & 32.8 & 688.3 & Unknown \\
Sample A & 7 & 0.39 & 40.9 & 1051.5 & Unknown \\
Sample A & 8 & 0.56 & 16.1 & 227.1 & Unknown \\
Sample A & 9 & 0.62 & 43.5 & 1685.4 & Glycoside 1 \\
Sample A & 10 & 0.70 & 12.2 & 279.4 & Unknown \\
Sample A & 11 & 0.92 & 264.6 & 14981.1 & Unknown \\
Sample A & 12 & 0.96 & 268.5 & 7975.3 & Unknown \\
STD & 1 & 0.73 & 150.3 & 2791.1 & Swertiamarin \\
\hline
\end{tabular}

A. lanata: Aerva lanata

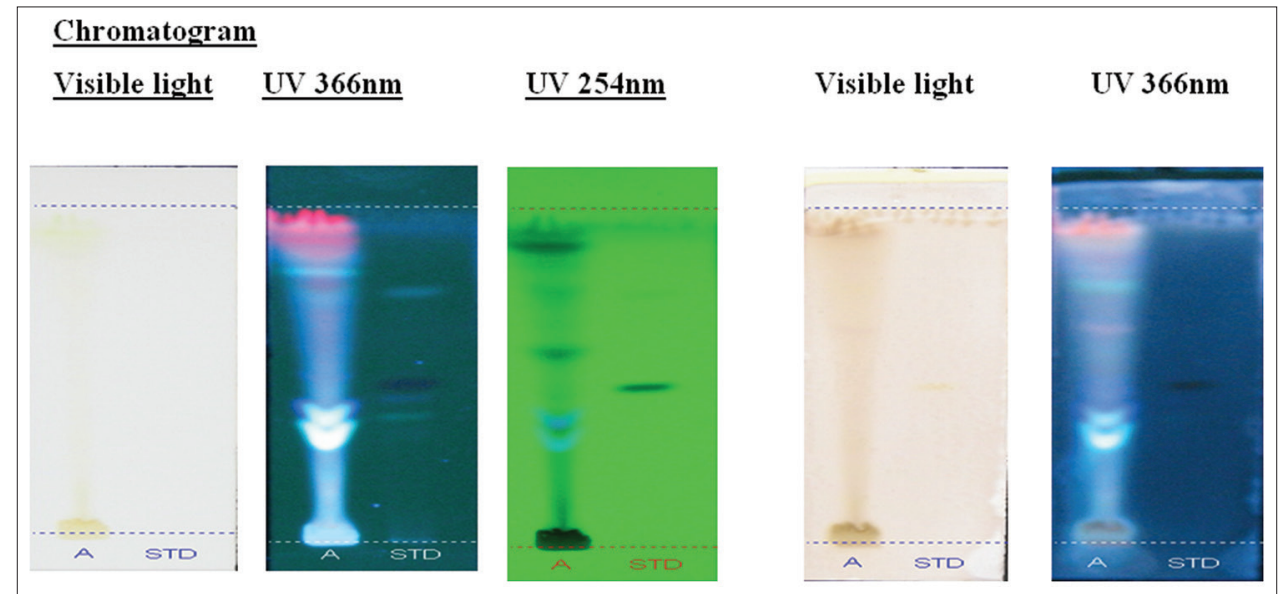

Fig. 4: High performance thin layer chromatography profile of the ethanolic extract of Aerva lanata and alkaloid standard (colchicine)

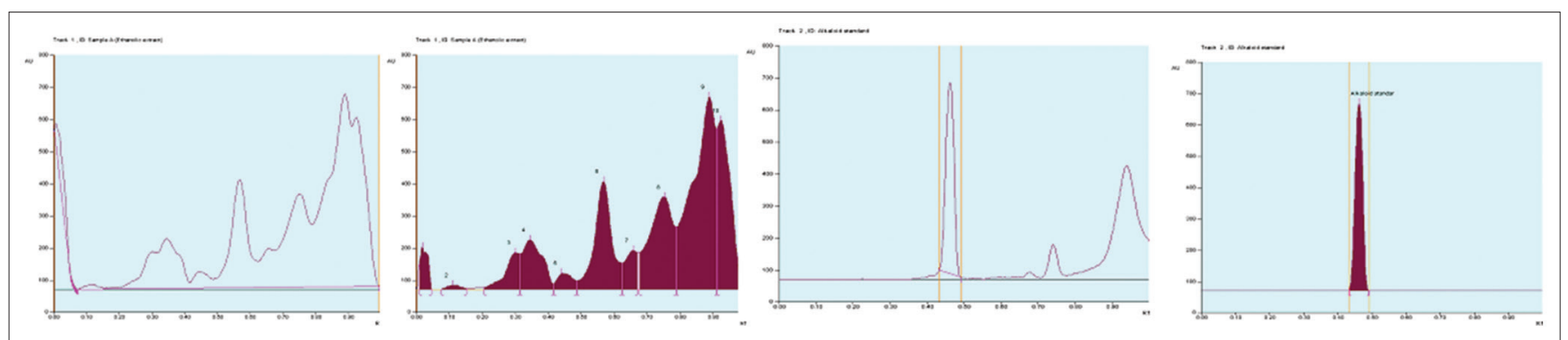

Fig. 5: High performance thin layer chromatography alkaloid chromatogram of Aerva lanata leaf and alkaloid standard (colchicine) - baseline display and peak densitogram display (scanned at $254 \mathrm{~nm}$ ) 
Table 4: Tannin profile of the ethanolic extract of the leaf of A. lanata

\begin{tabular}{llllll}
\hline Track & Peak & Rf & Height & Area & $\begin{array}{l}\text { Assigned } \\
\text { substance }\end{array}$ \\
\hline Sample A & 1 & 0.07 & 23.4 & 431.4 & Tannin 1 \\
Sample A & 2 & 0.15 & 44.1 & 956.0 & Unknown \\
Sample A & 3 & 0.26 & 82.6 & 5602.3 & Unknown \\
Sample A & 4 & 0.38 & 94.1 & 4464.5 & Unknown \\
Sample A & 5 & 0.64 & 400.1 & 36105.5 & Tannin 2 \\
Sample A & 6 & 0.69 & 449.7 & 13767.3 & Tannin 3 \\
Sample A & 7 & 0.73 & 574.2 & 22029.0 & Tannin 4 \\
Sample A & 8 & 0.80 & 307.2 & 15856.7 & Unknown \\
Sample A & 9 & 0.93 & 157.2 & 8990.1 & Unknown \\
STD & 1 & 0.55 & 391.4 & 11243.1 & Gallic acid \\
\hline
\end{tabular}

A. lanata: Aerva lanata

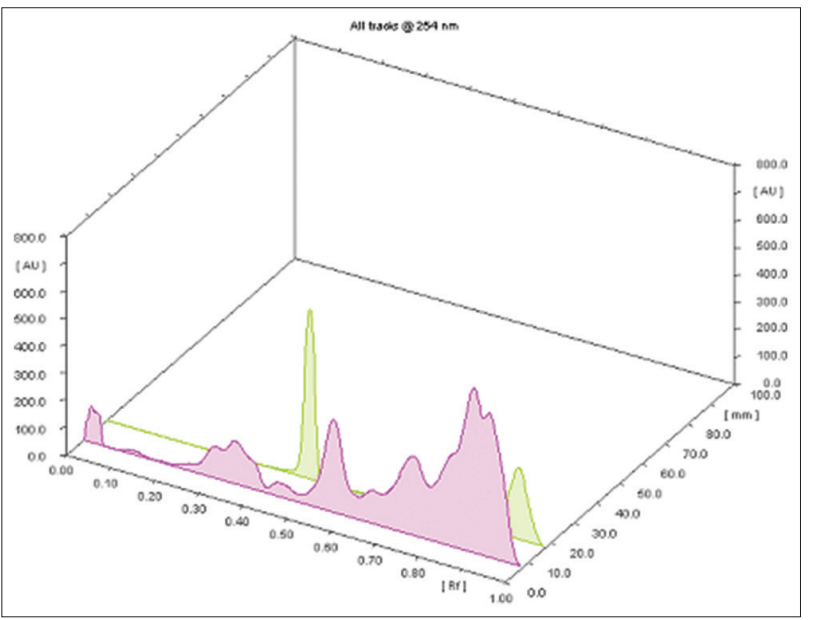

Fig. 6: 3D display of high performance thin layer chromatography alkaloid chromatogram of Aerva lanata

\section{DISCUSSION}

Authentication of medicinal plants in genetic and chemical level is a critical step in the use of these botanical materials for research and commercial preparations. For any living organisms, identity is very important to distinguish itself from other organisms within the populations and other populations. In plant taxonomy, during this molecular era, the morphological characters also play a key role in plant systematic study and are used as a tool for the classification of taxonomy [2].

Phenolic acids are aromatic secondary plant metabolites, studied mainly for their properties against oxidative damage leading to various degenerative diseases, such as cardiovascular diseases, inflammation, and cancer $[4,5]$. Varied biological activities of phenolic acids were reported. It increases bile secretion, reduces blood cholesterol and lipid levels and antimicrobial activity against some strains of bacteria such as Staphylococcus aureus are some of biological activities of phenolic acids [6].

Tannins are a heterogeneous group of high molecular weight polyphenolic compounds with the capacity to form reversible and irreversible complexes with proteins, polysaccharides, alkaloids, nucleic acids, minerals, etc. Based on structural characteristics it is divided into four major groups gallotannins, ellagitannins, complex tannins, and condensed tannins. Tannins are widely used in the dyestuff industry as caustics for cationic dyes and also in the production of inks. Tannins in the form of proanthocyanidins have a beneficial effect on vascular health $[7,8]$. Tannins are used as astringents, stimulant, antiseptics, diuretics, wound healer, and antiulcer. They are useful as an anti-inflammatory agent and in the treatment of burns and other wounds based on their antihemorrhagic and antiseptic potentials [9-10].

Alkaloids are a natural product that contains heterocyclic nitrogen atoms. Alkaloids are naturally synthesis by large numbers of organisms, including animals, plants, bacteria, and fungi.

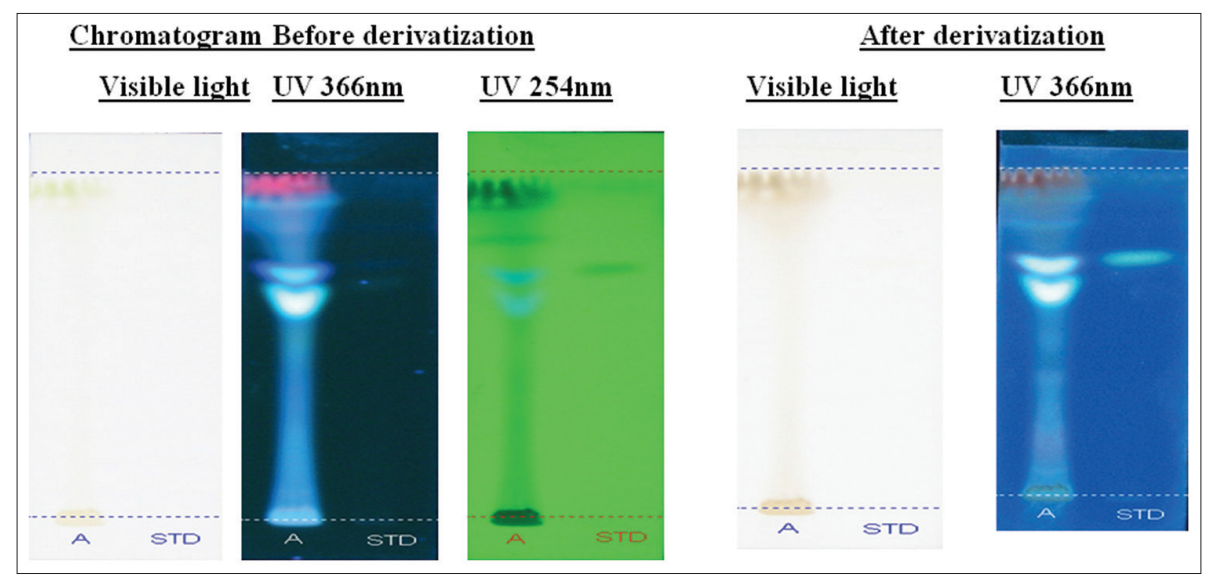

Fig. 7: High performance thin layer chromatography profile of the ethanolic extract of Aerva lanata and glycoside standard (Swertiamarin)

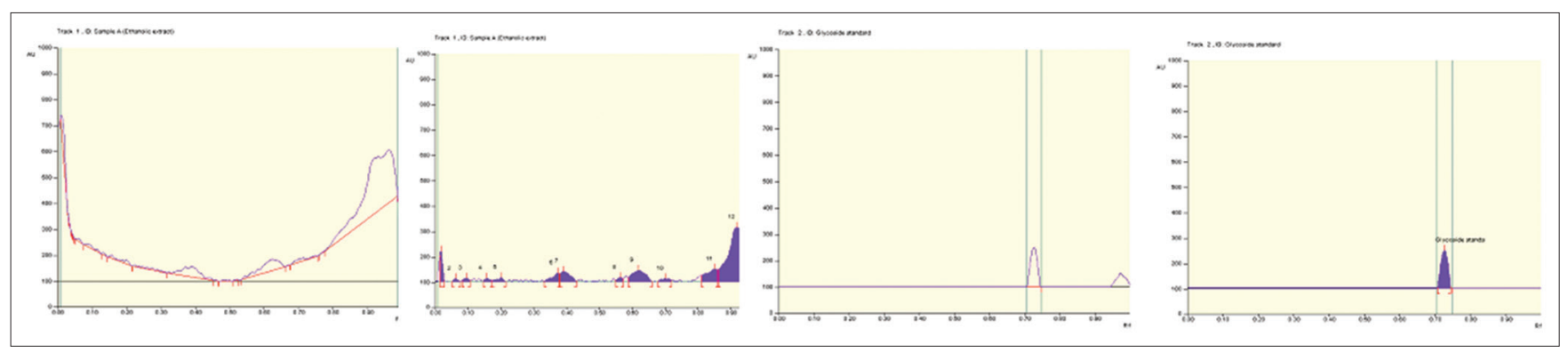

Fig. 8: High performance thin layer chromatography glycoside chromatogram of Aerva lanata leaf and glycoside standard (Swertiamarin) - Baseline display and peak densitogram display (scanned at $254 \mathrm{~nm}$ ) 
Alkaloids in nature are significant for the protecting and survival activity of plant because they ensure their survival against microorganisms, insects, and herbivores [11,12]. Alkaloids have many pharmacological activities including antihypertensive effects, antiarrhythmic effect, antimalarial activity, and anticancer actions. Some alkaloids have stimulant property as caffeine and nicotine, morphine are used as the analgesic and quinine as the antimalarial drug [13-15].

The result of this study showed and confirmed the presence of 11 different types of phenol with 11 different $\mathrm{Rf}$ values with range 0.06-0.95, 10 different types of alkaloid with 10 different Rf values

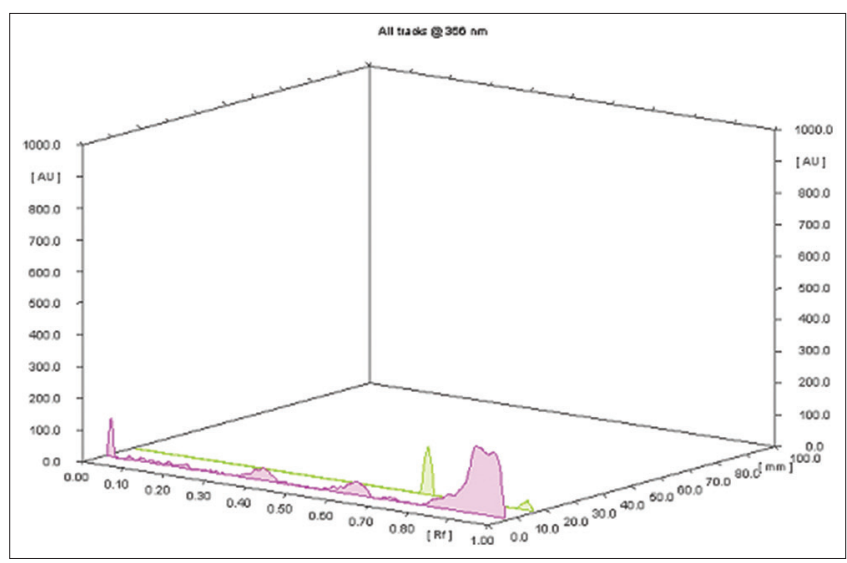

Fig. 9: 3D display of high performance thin layer chromatography glycoside chromatogram of Aerva lanata from 0.02 to $0.92,12$ different types of glycoside with 12 different $\mathrm{Rf}$ values from 0.02 to $0.96,9$ different types of tannin with 9 different $\mathrm{Rf}$ values from 0.07 to 0.93 . The developed HPTLC fingerprint will help the manufacturer for the quality control and standardization of herbal formulations.

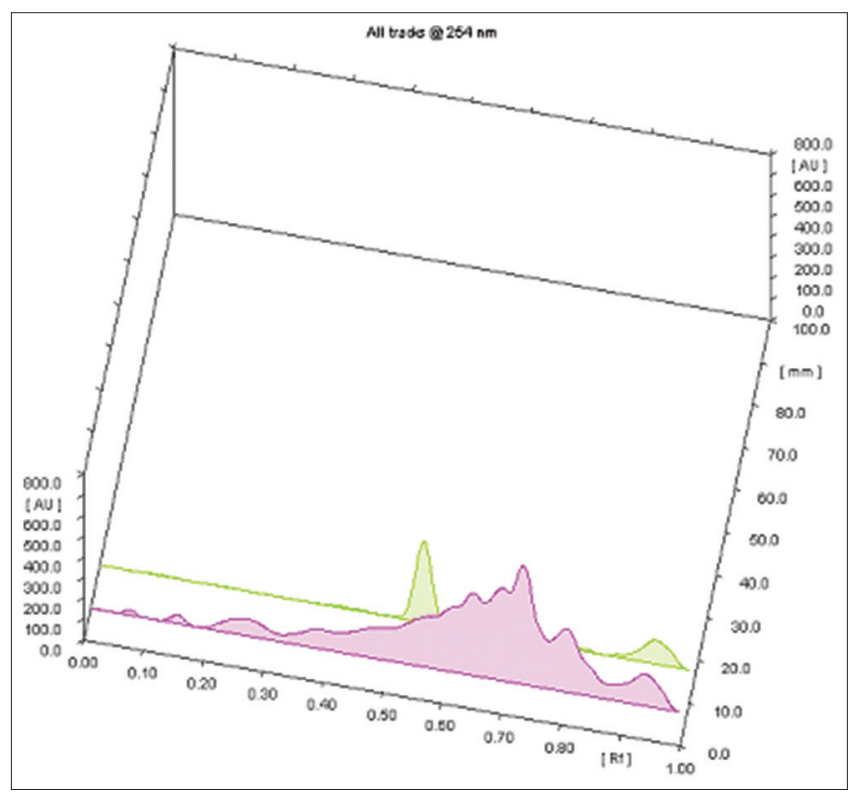

Fig. 12: 3D display of high performance thin layer chromatography Tannin chromatogram of Aerva lanata

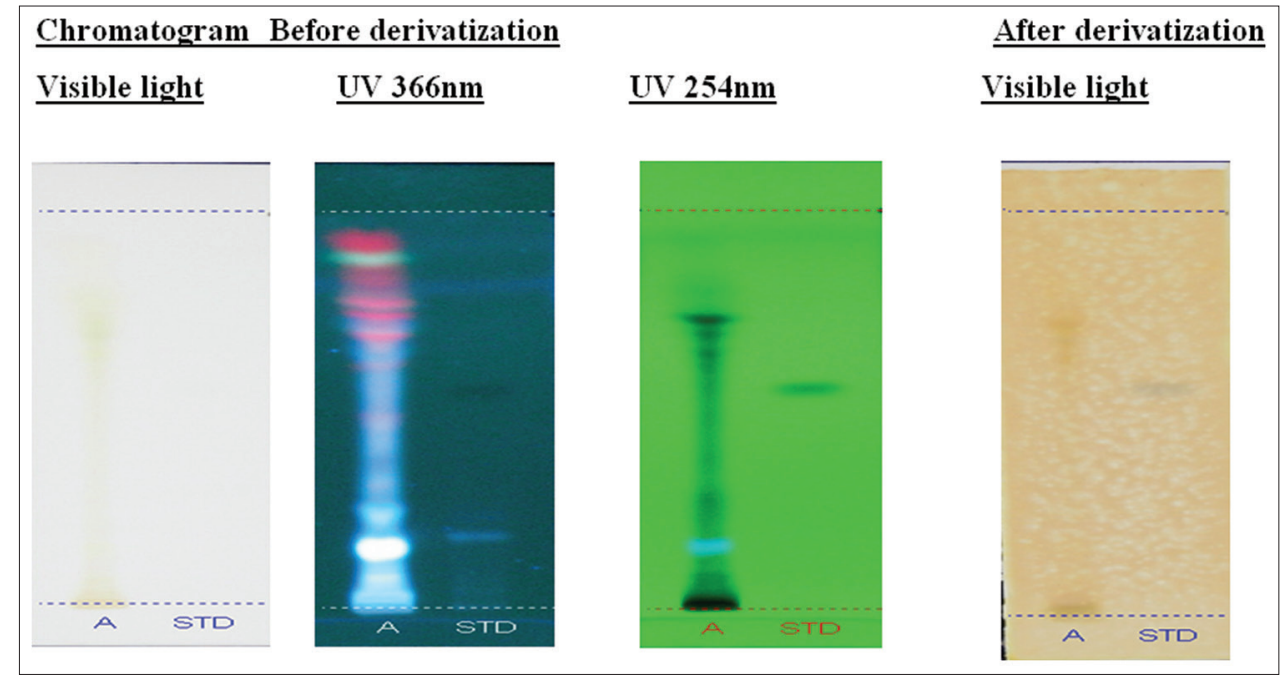

Fig. 10: High performance thin layer chromatography profile of the ethanolic extract of Aerva lanata and tannin standard (gallic acid)

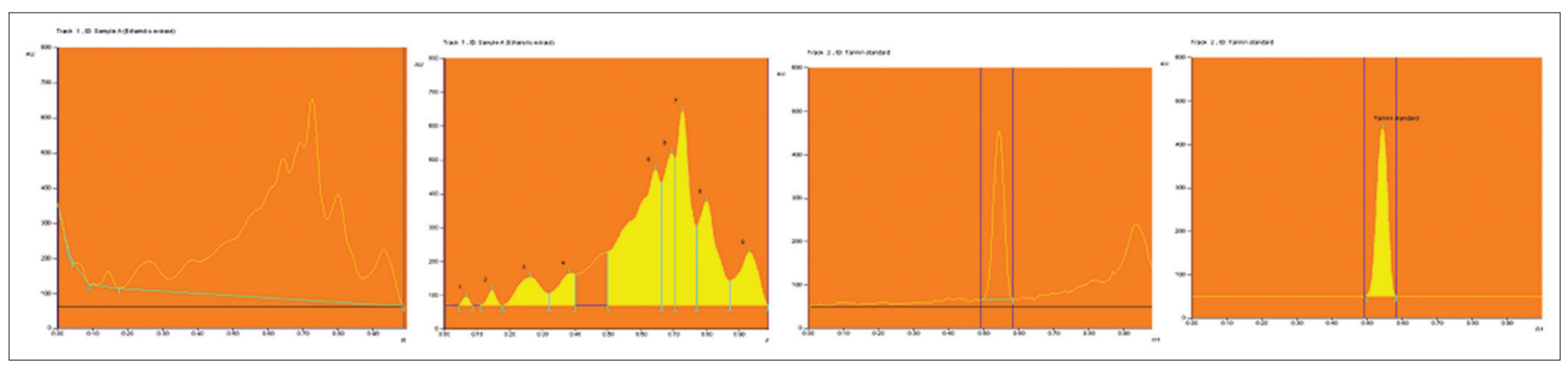

Fig. 11: High performance thin layer chromatography tannin chromatogram of Aerva lanata leaf and tannin standard (tannic acid) - baseline display and peak densitogram display (scanned at $254 \mathrm{~nm}$ ) 


\section{CONCLUSION}

The result of this study provided a valuable phytomarker for the identification and characterization of A. lanata. Further, pharmacological studies are going to isolate, identify, characterize, and elucidate the structure of the bioactive compound.

\section{REFERENCES}

1. Szepesi G. Some aspect of the validation of planar chromatographic methods used in pharmaceutical analysis. I. General principles and practical approaches. J Planar Chromatogr 1993;6(3):187-9.

2. Harborne JB. Phytochemical Methods. $3^{\text {rd }}$ ed. London: Chapman and Hall; 1998.

3. Bajaj YP. Medical and Aromatic Plants: Biotechnology in Agriculture and Forestry. Berlin: Springer-Verlag; 1988. p. 24.

4. Adebajo AO, Adewumi CO, Essein EE. Anti-infective agents of higher plants. International Symposium of Medicinal Plants. $5^{\text {th }}$ ed. Nigeria: University of Ife; 1983. p. 152-8.

5. Kim D, Jeond S, Lee C. Antioxidant capacity of phenolic phytochemicals from various cultivars of plums. Food Chem 2003;81(3):321-6.

6. Gryglewski RJ, Korbut R, Robak J, Swies J. On the mechanism of antithrombotic action of flavonoids. Biochem Pharmacol 1987;36(3):317-22.
7. Schofield P, Mbugua DM, Pell AN. Analysis of condensed tannins: A review. Anim Feed Sci Technol 2001;91:21-40.

8. Vansoest PJ. Nutritional Ecology of the Ruminant. $2^{\text {nd }}$ ed. Ithaca, NY: Cornell University Press; 1994. p. 476

9. Mueller-Harvey I, Mcallan AB. Tannins: Their biochemistry and nutritional properties. In: Morrison IM, editor. Advances in Plant Cell Biochemistry and Biotechnology. London, UK: JAI Press Ltd.; 1992. p. 151-217.

10. Mangan JL. Nutritional effects of tannins in animal feeds. Nutr Res Rev 1988;1(1):209-31.

11. Mc-Leod MN. Plant tannins: Their role in forage quality. Nutr Abstr Rev 1974;44:803-12.

12. Gyamfi MA, Aniya Y. Antioxidant properties of Thonningianin A, isolated from the African medicinal herb, Thonningia sanguinea. Biochem Pharmacol 2002;63(9):1725-37.

13. Pujari L, Sodimbaku V. Urolithiasis-an updated review over genetics, pathophysiology and its clinical management. Int J Pharm Pharm Sci 2014;6(11): 23-31.

14. Patel P, Patel N, Patel D, Desai S, Meshram D. Phytochemical analysis and antifungal activity of Moringa oleifera. Int J Pharm Pharm Sci 2014;6(5):144-7.

15. Patel P, Patel N, Patel D, Desai S, Meshram D. Phytochemical analysis and antifungal activity of Moringa oleifera. Int J Pharm Pharm Sci 2014;6(5):144-7. 